\title{
Stres üriner inkontinans hastalarında midüretral transobturator bant cerrahisi: Klinik gözlem ve erken dönem sonuçları
}

\author{
In stress urinary incontinence patients, evalution of transobturator tape \\ procedure: Clinical observation and early results
}

\author{
Ayhan Aksoy, Hakan Nazik*, Raziye Narin, Mehmet Ali Narin, Hakan Aytan, \\ Murat Api
}

Kadın Hastalıkları ve Doğum Kliniği (Dr. A. Aksoy), Kilis Devlet Hastanesi, TR-79000 Kilis. Kadın Hastalıkarı ve Doğum Kliniği (Dr. H. Nazik, Dr. R. Narin, Dr. M. A. Narin), Adana Numune Eğitim ve Araştırma Hastanesi, TR-01330 Adana. Kadın Hastalıkları ve Doğum Anabilim Dalı (Doç. Dr. H. Aytan), Mersin Üniversitesi Tıp Fakültesi, TR-33070 Mersin. Kadın Hastalıkları ve Doğum Kliniği (Doç. Dr. M. Api), Zeynep Kamil Eğitim ve Araştırma Hastanesi, TR-34668 İstanbul.

\section{Özet}

Amaç. Stres üriner inkontinans (SUI) olgularında, Transobturator bant (TOT) operasyonunun sonuçlarının ve komplikasyonlarının, klinik ve yaşam kalitesi analizi yapılarak değerlendirilmesi. Yöntem. SUI veya mikst üriner inkontinans (MUI) tanısı ile TOT yapılan 30 hasta çalışmaya

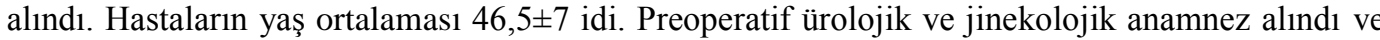
jinekolojik muayene, ultrasonografi, stres test, Q tip test yapıldı, inkontinans anketleri dolduruldu. TOT operasyonu monoflaman tape kullanılarak dıştan içe yöntem kullanılarak yapıldı. Hastaların postoperatif dönemde tüm klinik ve laboratuar bulguları değerlendirilerek preoperatif parametreler ile karşılaştırıldı. Operasyondan sonra hastaların ortalama takip süresi 16,7 aydı. Sonuçlar Wilcoxon signed rank testi ile istatistiksel anlamlllık açısından değerlendirildi. Bulgular. Sekiz hastada $(\% 26,7)$ SUI, 22 hastada $(\% 73,3)$ MUI mevcuttu. TOT ameliyatına ek olarak $6(\% 30)$ hastaya kolporafi anterior (KA), $1(\% 3,3)$ hastaya kolporafi posterior (KP), $12(\% 40)$ hastaya KA ve KP $2(\% 6,6)$ hastaya vaginal histerektomi, KA, KP uygulanmıştır. Bir hastada mesane perforasyonu, bir hastada postoperatif urge inkontinans görüldü. TOT operasyonu ile hastaların 26 'sında $(\% 86,7)$ başarılı olunurken, dördünde $(\% 13,3)$ başarısız olunmuștur. Yaşam kalitesi değerlendirilmesinde IIQ-7 (Incontinence impact questionnaire) ve UDI-6 (Urinary distress inventory) skorlarında istatistiksel olarak anlamlı düzelme saptanmıştır ( $\mathrm{P}<0,001$ ve $\mathrm{P}=0,026)$. Sonuç. Bu çalışmada, SUI tedavisinde TOT uygulaması ile yüksek objektif iyileşme ve yaşam kalitesinde anlamlı düzelme sağlandığı saptanmıştır. Uygulama kolaylığı ve komplikasyon oranının düşük olması sebebiyle TOT operasyonunun diğer inkontinans cerrahi prosedürlerine iyi bir alternatif olduğu sonucuna varılmıştır.

Anahtar sözcükler: Stres üriner inkontinans, midüretral transobturator bant, TVT

\begin{abstract}
Aim. In stress urinary incontinence patients (SUI), the evalution of the results and complications of Transobturator tape (TOT) procedure by using clinical and life quality analysis. Method. 30 patients, who are diagnosed as SUI or MUI and operated with TOT procedure were included in the study. The mean patient age was $46.5 \pm 7$. Preoperative urological and gynecological histories were taken; gynecological examination, ultrasonography, stres test, Q tip test were performed. Incontinence questionnaires were filled. TOT procedure was performed to all 30 patients by using monofilament tape with outside-in technique. The mean postoperatif follow-up was 16.7 months. In the postoperative period all patients' clinical and laboratory tests were repeated and compared with the preoperative parameters. Results were evaluated with Wilcoxon signed rank test for statistical significance. Results. Eight (26.7\%) patients had SUI, 22 (73.3\%) patients had MUI. No additional operations were performed to nine (30\%) patients. In addition to TOT, six (20\%) of patients had colporraphy anterior (CA), twelve (40\%) patients had CA and colporraphy posterior (CP), $1(3.3 \%)$ patient had CP, two $(6.6 \%)$ patients had vaginal hysterectomy (VAH) and CA+CP. Intraoperative one $(3.3 \%)$ bladder perforation has occured. Postoperative one patient had de nove urge. While TOT procedure was successful in 26-cases $(86.7 \%), 4(13.3 \%)$ of them have failed. In
\end{abstract}


the life quality analysis IIQ-7 (Incontinence impact questionnaire) and UDI-6 (Urinary distress inventory) scores showed significant improvement $(\mathrm{P}<0.001$ ve $\mathrm{P}=0.026)$. Conclusion. Our study confirmed high objective cure rate, improvement of symptoms and quality of life with TOT operation. These results suggest that the transobturator tape procedure is a valueable alternative to the other surgical procedures in SUI, with a low rate of complications and convenience of learning and application.

Keywords: Stress urinary incontinence, transobturator tape, TVT

Geliş tarihi/Received: 05 Mart 2013; Kabul tarihi/Accepted: 08 Ekim 2013

*İletişim adresi:

Dr. Hakan Nazik, Kadın Hastalıkları ve Doğum Kliniğgi, Adana Numune Eğitim ve Araştırma Hastanesi TR-01330 Adana. E-posta: drhakannazik@gmail.com

\section{Giriş}

Üriner inkontinans, Uluslararası Kontinans Derneği (ICS) tarafindan sosyal ya da hijyenik sorun haline gelen ve objektif olarak gösterilebilen istem dış1 idrar kaçırma olarak tanımlanır [1]. Ortalama yaşam süresinin arttığı ve yaşam kalitesinin daha da önem kazandığ 1 günümüzde üriner inkontinans ciddi bir sağlık sorunu olarak karşımıza çıkmaktadır. SUI detrusor aktivite artışı olmaksızın, intravezikal basıncın üretra basıncını aşmasıyla ortaya çıkan idrar kaçırma şekli olarak tanımlanır [1]. SUI, dünyadaki 30-60 yaş arasındaki tüm kadınların dörtte birinden fazlasını etkilemektedir. Avrupa ülkelerindeki SUI prevelans1 \%35 kadardır [2]. Biri ve ark. [3]'nın, ülkemizde 15 yaş ve üzeri 2601 kadında yaptıkları çalışmada; SUI prevalansı \%16,1 olarak bildirilmiştir.

SUI tedavisinde Burch kolposüspansiyon ameliyatı hala yaygın olarak uygulanmakla birlikte [4], günümüzde üretranın altına hamak şeklinde destek sağlayarak üretrovezikal bileşkeyi stabilize etmeyi amaçlayan birçok cerrahi tedavi yöntemi tarif edilmiştir. İntegral teoriyi temel alarak, Petros ve Ulmsten [5], 'tension free vaginal tape (TVT) prosedürünü ortaya koymuşlardır. Mid-üretranın sıkı olmayan bir şekilde desteklenmesi sağlayan bu teknik, inkontinansta $\% 80$ 'den fazla kür sağlamıştır [6]. TVT prosedürünün Burch kolposüspansiyon ile eşit etkinliğe sahip olduğu gösterilmiştir [7, 8].

TVT cerrahisinde komplikasyonların en s1k retropubik alan diseksiyonunda görülmesi üzerine, alternatif teknikler geliştirme ihtiyacı doğmuştur. TVT yöntemi ile iğnenin retropubik boşluktan körlemesine geçişinin yerini, tape'in iki obturator foramen arasına yerleştirilmesi (transobturator bant yöntemi (TOT)) almıştır. Bu yaklaşım ilk kez Delorme tarafından 2001'de tarif edilmiş ve kontinans sağlama başarısının retropubik TVT tekniği ile benzer olduğu bulunmuştur [9-11]. TOT tekniği ile komplikasyon oranları azalmış [12], kolay öğrenilmesi ve tedavideki etkinliği nedeniyle inkontinans cerrahisinde daha geniş yer bulmaya başlamıştır.

$\mathrm{Bu}$ çalışmada, SUI tedavisinde TOT prosedürünün etkinliğini araştırmak, komplikasyon sıklığını ve hastaların yaşam kalitesine etkilerini değerlendirmek amaçlanmıştır.

\section{Gereç ve yöntem}

Çalışmaya Şubat 2009-Aralık 2009 tarihleri arasında Sağlık Bakanlığı Sağlık Bakanlığı Adana Numune Eğitim ve Araştırma Hastanesi Kadın Hastalıkları ve Doğum Kliniğine stres durumlarında idrar kaçırma şikayeti ile başvuran 30 hasta alındı. Hastaların yaşları 28 ile $59(46,5 \pm 7)$ arasında idi. Hastaların demografik özellikleri, yaşam kalite skorları (Incontinence impact questionnaire (IIQ-7) ve Urinary distress inventory (UDI-6)), muayene bulguları, nörolojik değerlendirme (klitoral refleks, anal refleks ve öksürük refleksi), stres test, stres öksürük testi, Q tip test, günlük ped sayısı, ultrasonografi, operasyon ve sonuçları kaydedildi. Olguların tamamından idrar tetkiki ve idrar kültürü istendi. 
Hastalar taburcu olduktan sonra ortalama 16,7 ay sonra komplikasyon, yaşam kalite skorları IIQ-7 ve UDI-6, muayene bulguları, nörolojik değerlendirme (klitoral refleks, anal refleks ve öksürük refleksi), stres test, stres Q tip test, günlük ped sayısı ile hastalar tekrar değerlendirildi. Her katılımcıya sözlü ve yazılı olarak çalışma hakkında bilgi verilip aydınlatılmış onam alındı.

Tüm hastalara genel anestezi uyguland. Litotomi pozisyonu verildikten sonra vulva, vajina ve perinenin povidon iyot ile temizliğini takiben Foley kateter ile mesane boşaltıldı. TOT prosedürü Delorme'nin tarif ettiği şekilde dıştan içe teknik ile uygulandı [10]. Üretral meatusun $0,5 \mathrm{~cm}$ altından başlanarak vajen ön duvarına yaklaşı $2 \mathrm{~cm}$ longitudinal insizyon yapıldı. Künt ve keskin diseksiyonla iskiopubik ramusun altına kadar periüretral disseksiyon yapıldı. Klitoris seviyesinde, labium majusun lateral kenarına, iskiyopubik ramusun $15 \mathrm{~mm}$ lateraline bilateral $5 \mathrm{~mm}$ insizyon yapıldı. Kanca şeklindeki TOT iğnesi, paraüretral disseksiyon yerindeki işaret parmağımızla iskiyopubik ramusun posterioru ve m.obturatorius internus palpe edilerek, mediale doğru ilerletildi ve sirayla ciltten, obturator membrandan ve vajendeki insizyondan geçirildi. $\mathrm{Bu}$ işlem sonrasında vajinal forniks ve üretra perforasyonu olup olmadığ 1 kontrol edildi. Ardından meş ile tutturulan iğne ters yönden çekilerek meş ciltten çıkarıldı. Aynı yöntem diğer tarafa uygulandı. Meşin gerginliği prosedürün sonunda üretra ile bant arasında makas ucu girecek kadar bir açıklık bırakılarak ayarlandı. Prosedürün sonunda 18 F Foley kateter yerleştirildi ve 1'inci gün çekildi. TOT ve varsa ek cerrahi işlemin süreleri kaydedildi.

Perioperatif komplikasyonlar, kullanılan bant materyali, ateş, analjezik ihtiyacı, kateterizasyon süresi ve hastanede kalış süreleri not edildi. İşeme güçlügü ve $100 \mathrm{cc}$ 'den fazla rezidü olup olmadığı değerlendirildi. Hastalar idrar rezidüsü $100 \mathrm{~mL}$ 'nin altında olduğunda taburcu edildi. Operasyon sonrası ilk 15 gün süresince olan komplikasyonlar erken komplikasyonlar olarak, devam eden veya 15 günden sonra ortaya çıkan komplikasyonlar ise geç komplikasyonlar olarak kabul edildi. Postoperatiferatif takip 1220 ay arasında idi. Operasyon sonrası stres test negatif bulunan, rezidüsü 100cc'nin altında olanlar ve tam kontinans sağlananlar 'kür' olarak değerlendirildi. İnkontinans sıklığı azalanlar ama hala kaçak tarif edenler 'kısmi iyileşme' olarak değerlendirildi. 'Kür' ve 'kısmi iyileşme' olarak değerlendirilenler başarılı kabul edildiler. Operasyon sonrası hiç değişiklik olmadığını söyleyen ve inkontinansı devam edenler 'başarısız' kabul edildi. Rezidü idrar tayini USG ile yapıldı.

Veri analizleri Statistical Package for Social Sciences (SPSS Inc, Chicago, Illinois, USA) 15,0 paket programı ile yapıldı. Numerik veriler sürekli ve kesikli değerler olarak toplandı. Verilerin merkezi dağılım ölçütü olarak ortalama ve ortanca kullanıldı, yaygınlık ölçütü olarak, standart sapma ve minimum, maksimum değerleri kullanıldı. Varsayımların karşılanması durumunda verilere korelasyon testi olarak Pearson, karşılanmadığı durumlarda Spearman korelasyon testi uygulandı. İstatistiksel anlamlılık olarak $\mathrm{P}<0,05$ değeri alındı. Hipotez sıfır olarak "TOT ameliyatı öncesi ve sonrasında yaşam kalitesi değerlendirme skalaları olan IIQ-7 ve UDI-6 bakımından, rezidüel idrar ve ped sayısı bakımından fark yoktur" hipotezi kuruldu.

\section{Bulgular}

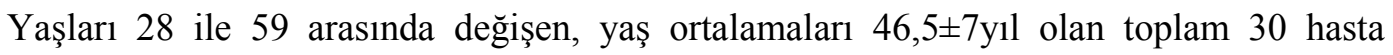
çalışmaya alındı. Hastaların post operatif takip süreleri 12 ay ile 20 ay arasında değişmekte olup ortalama takip süresi 16,7 aydı. Hastaların parite ortalamaları $4 \pm 1,6$ (min.; 0, max.; 8) idi; 29 hasta vajinal yolla doğum yapmıştı. Bir hasta hiç doğum yapmamıştı. Ayrıca 4 hasta sezaryen ile doğum yapmıştı. Vücut kitle indeksi ortalama $31 \pm 3,1 \mathrm{~kg} / \mathrm{m}^{2}$, menopozda olan hasta say1s1 $7(\% 23,3)$ idi. Menopozda olan hastaların menopoz süreleri 3 ile 10 yıl arasında değişmekle birlikte ortalama süre 4,7 yıl idi. Menopozdaki hastalardan hiç biri Hormon replasman tedavisi (HRT) almamıştı. Operasyon öyküleri değerlendirildiğinde hastaların, kolporafi anterior (1 hasta), kolporafi anterior ve kolporafi posterior (1 hasta), myomektomi (1 hasta) olduğu görüldü. Üç 
hastanın desensus uteri düzeyi Grade I iken; ikisinin Grade II idi. Sistosel düzeylerinin dağılımına bakıldığında 2'sinin $(\% 6,6)$ Grade I, 15'inin(\%50) Grade II ve 4'ünün $(\% 13,3)$ Grade III olduğu görüldü. Rektosel düzeylerinin dağılımına bakıldığında 5 hastanın Grade I $(\% 16,6), 15$ hastanın Grade II olduğu görüldü.

Operasyon öncesinde rezidü idrar, kullanılan günlük ped sayısı ve Q-tip test bulguları,

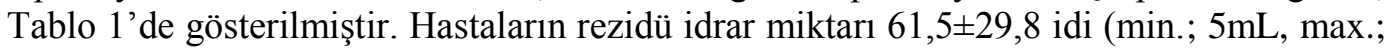
$130 \mathrm{~mL}$ ). Hastaların preoperatif Q-tip test sonuçları 20 ile 80 derece arasında değişmekle

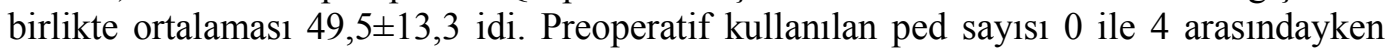
ortalama $1,1 \pm 1,1$ idi. Hastaların tamamında stres inkontinans görülürken; 22 $(\% 73,3)$ 'sinde ek olarak urge inkontinans da görülmüştür. Hastaların 9 tanesine $(\% 30)$ TOT dışında ek bir müdahalede bulunulmamıştır. Ek olarak altı hastaya (\%20) kolporafi anterior (CA), oniki (\%40) hastaya kolporafi posterior $(\mathrm{CP})+\mathrm{CA}$, bir $(\% 3,3)$ hastaya $\mathrm{CP}$, iki $(\% 6,6)$ hastaya vajinal histerektomi $\mathrm{CA}+\mathrm{CP}$ operasyonları uygulanmıştır (Şekil 1). Operasyon süresi 12 dakikayla 20 dakika arasıdır (ek operasyon süresi dahil değildir). Hastaların Postoperatif hospitalizasyon süreleri 1 ile 7 gün arasında değişmektedir. Postoperatif kateterizasyon süresi 29 hastamızda 1 gün olup intraoperatif mesane yaralanması olan bir hastamızda 7 gün tutulmuştur.

Tablo 1. Preoperatif rezidü idrar, kullanılan ped sayısı ve Q-tip test ortalamaları.

\begin{tabular}{llll}
\hline & Ort \pm SD & Minimum & Maksimum \\
\hline Rezidü idrar & $61,5 \pm 29,8$ & 5 & 130 \\
Q-tip test (o) & $49,5 \pm 13,3$ & 20 & 80 \\
Ped say1S1 & $1,1 \pm 1,1$ & 0 & 4 \\
\hline
\end{tabular}

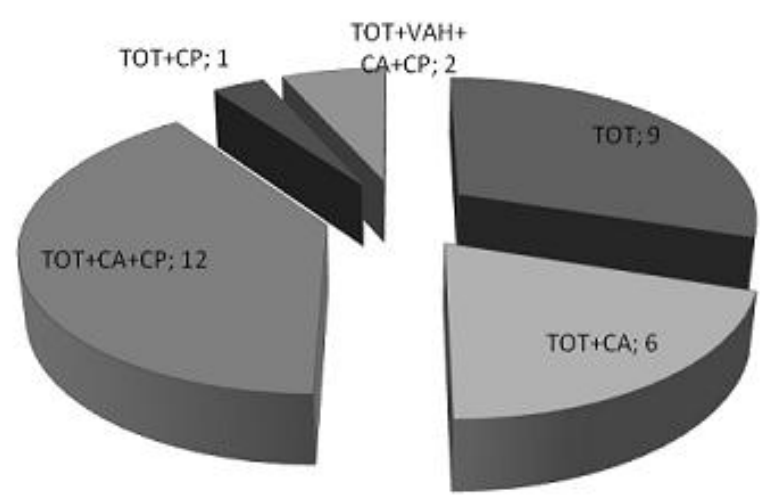

Şekil 1. Uygulanan operasyon çeşitleri.

Hastaların birinde $(\% 3,3)$ peroperatif mesane yaralanması görülürken, postoperatif komplikasyonların dağılımı; iki hastada $(\% 3,3)$ denova urge inkontinans, bir hastada $(\% 3,3)$ 1kınarak işeme, bir hastada $(\% 3,3)$ disparoni olarak görülmüştür. Hayat kalitesi değerlendirilmesi IIQ-7 ve UDI-6 anketleri ile yapılmıştır. Her iki testte de preoperatif verilere göre postoperatif verilerde istatistiksel anlamlı düzelme saptanmıştır (Tablo 2). Preoperatif ve postoperatif kullanılan ped sayıları ve ölçülen rezidü idrar miktarları arasında anlamlı bir azalma vardı (Tablo 2).

Tablo 2. IIQ-7 ve UDI-6 anketleri, ped sayısı ve rezidü idrar karşılaştırmaları.

\begin{tabular}{llll}
\hline & Preoperatif & Postoperatif & P değeri \\
\hline IIQ-7 & $12,5 \pm 3,2$ & $4,1 \pm 3$ & 0,004 \\
UDI-6 & $9,2 \pm 2,2$ & $2,8 \pm 1,8$ & 0,026 \\
Ped say1s1 & $1,1 \pm 1,1$ & $0,3 \pm 0,6$ & $\mathrm{P}<0,001$ \\
Rezidü & $61,5 \pm 29,8$ & $34,1 \pm 20,2$ & 0,020 \\
\hline
\end{tabular}

İdrar kaçırmanın günlük hayata olumsuz etkisi ve ruhsal durum üzerine etkisini araştıran IIQ-7 ve UDI-6 anket sonuçlarında, preoperatif döneme göre postoperatif dönemde 
istatistiksel olarak anlamlı düzelme görülmüştür $(\mathrm{P}<0,001$ ve $\mathrm{P}=0,026)$. TOT operasyonu ile hastaların 26'sında $(\% 86,7)$ başarılı olunurken, dördünde $(\% 13,3)$ başarısız olunmuştur.

\section{Tartışma}

Stres üriner inkontinansın tedavisinde kullanılan cerrahi yöntemler esas olarak üretrovezikal bileşkenin yukarı kaldırılması ve desteklenmesi prensibine dayanır. Üriner inkontinans operasyon teknikleri kolposüspansiyon, kolporafi anterior, sling prosedürleri ve iğne süspansiyonları olmak üzere 4 ana grupta toplanmaktadır [5]. Uygulanan cerrahi yöntemlerin fazla olması, etkinliklerinin değerlendirmesindeki farklı ölçütler ve postoperatif izlem süresindeki farkl11ıklar hangi yöntemin daha iyi olduğunun belirlenmesini zorlaştırmaktadır.

Tension free midüretral slingler (TVT) ilk kez 1996 yılında tanıtılmış ve uygulamaya geçilmiştir. TVT ile Burch operasyonunun karşılaştırıldığ çok merkezli randomize bir çalışmada, postoperatif iki yıl sonunda objektif kür oranları TVT'de \%63 ile \%85 arasında, Burch'de \%51 ile \%87 arasında saptanmıştır [13]. Aynı çalışmada 5 yıllık kür oranları TVT'de \%81, Burch'de \%90 olarak saptanmıştır.

TVT yöntemine alternatif olarak sunulan ve 1996'dan beri uygulama alanı bulan TOT uygulaması etkinlik ve komplikasyon açısından olumlu sonuçlar ortaya koymuştur. TOT operasyonu, TVT'nin olası komplikasyonlarından bağımsız fakat aynı etkinlikte bir yöntemin arayışı içinde 2001 yılında Delorme tarafından tarif edilmiştir. Bu yöntemde retropubik yaklaşımla yapılan midüretral slinglere göre teorik olarak pelvik organ yaralanma riski daha düşüktür [9]. Bu prosedürde silikon ile kaplanmış, örülmemiş poliprolen yapıda ve esnemeyen özellikteki destek, obturator ile puborektal kasın içinden geçerek doğal bir süspansiyon oluşturmaktadır. TOT iğnesi diştan içe doğru hareket ettirilerek uygulanan bu cerrahi yöntem daha sonra komplikasyon oranlarını azaltmak için de Laval tarafından modifiye edilmiştir. Modifiye teknikte iğne içten-dışa kullanılmış ve bu yöntem tension free vaginal tape obturator yol (TVT-O) olarak adlandırılmıştır. Yapılan çalışmalarda iki yöntem arasında gerek etkinlik gerekse de komplikasyon açısından fark bulunamamıştır [14].

Halen inkontinansta iyileşme kavramı veya tedavi sonrası sonuçları değerlendiren klinik yöntemlere ilişkin herhangi bir uzlaşı mevcut değildir. Stres inkontinans cerrahisinin objektif iyileşme oranları sıklıkla fizik muayene, ped testi veya ürodinamik araştırmayla belirlenmektedir. Ancak bu değerlendirmelerin tümü yalnızca o anlık kontinans durumunu yansıtmaktadır. Hastanın iyileşme düzeyinin inkontinans cerrahisinin sonuçları açısından önemli olduğu gösterilmiştir [15]. İnkontinansa ilişkin yaşam kalite testleri ürogenital semptomların tümünü araştırdığından işeme işlev bozukluğu veya aşırı aktif mesane semptomları gibi uzun dönemli komplikasyonları yansıtabilmektedir. Bu nedenle geçerliliği onaylanmış yaşam kalite sorgulama formlarının kullanılması önerilmektedir. Kliniğimizde yaşam kalite testleri olarak İnkontinansın Etkisini Sorgulama Formu (IIQ-7) ve Ürogenital Rahatsızlık Envanteri (UDI-6) kullanılmaktadır. Bu skalalar önceleri hastaların üriner inkontinans semptomlarının rapor edilmesi ve üriner inkontinansın hastaların yaşamları üzerine etkilerinin somut kanıtlarını elde etme amacıyla oluşturulmuştur. UDI-6 üriner semptomlar ve IIQ-7, fiziksel aktivite, yolculuk, sosyal ilişkiler ve ruhsal sağlık durumu gibi gündelik aktiviteler üzerine odaklanmış olduğundan bu iki test birbirini tamamlamaktadır. Yakın zamanda bu yaşam kalite testleri cerrahi sonrası kontinans durumunu değerlendirme araçları olarak sunulmuştur [16]. Bu çalışmada stres üriner inkontinansı olan TOT operasyonu uygulanan hastalarda yaşam kalitesini değerlendirmek için, geçerliliği onaylanmış duyarlı ve güvenli ölçekler kullanarak prosedürün işlevsel etkinliği ve hasta memnuniyetini gösterdik.

Biyomateryalin tipi ve özellikleri de prosedürün başarısı ve komplikasyon oranı için önemli bir faktördür. Meş çeşitleri, polimerin tipine, fiberlerin doğasına, ağırlığına, por genişliğine ve por düzenine göre ayrılır. Bu farklılıklar, in vivo reaksiyonların çok çeşitli 
komplikasyonlarıyla sonuçlanırlar. Böylece, biyokompabilitede değişikliklere ve enfeksiyon, erozyon veya rejeksiyon olasilıklarındaki farklılıklara neden olurlar [14]. Büyük por genişliği olan bantlar ile doku integrasyonu ve enfeksiyona direnç daha fazla olmaktadır. Çalışmada bant olarak \%100 monofilaman polipropilen makropor meş (IStop, CL Medical, France) kullanıldı.

Stres üriner inkontinans tedavisi için yapılan askı operasyonlarında üretral obstrüksiyon dikkat edilmesi gereken bir noktadır. TVT ve TOT gibi prosedürler 'tension-free' olarak tasarlandıklarından, postoperatif obstrüksiyon ve işeme güçlüğüne daha az rastlanır [17]. Sling operasyonlarında üretral mobilitenin düzeltilmesi gerekli değildir. Tersine üretral mobilitenin postoperatif devam etmesi üretranın stres esnasında dinamik olarak kıvrılmasını sağlar [18]. Bizim çalışmamızda da Q tip test ile yapılan ölçümlerde üretral mobilite devam etmekle beraber, istatistiksel olarak preoperatif ve postoperatif değerlerde anlamlı değişim görülmüştür.

Deval B ve ark. [19] tarafindan yapılan bir çalışmada; erken postoperatif idrar retansiyonu $(\% 1,5)$ ve işeme güçlügü $(\% 5,4)$ ile karşılaşılmıştır. Costa ve ark. [11] ve Delorme ve ark. [9] TOT sonras1, sirasıyla, yedi hastada $(\% 3,8)$ ve bir hastada $(\% 0,6)$ mesane çıkım obstrüksiyonu not etmişlerdir. Costa ve ark. [11] TOT sonrası klinik olarak belirgin obstrüksiyon varlığında, meşin olabildiğince erken gevşetilmesinin veya çıkarılmasının yararlı olabileceğini ifade etmişlerdir. Deval B ve ark. [19] tarafından yapılan çalışmada; postoperatif retansiyon gelişen hastalarda, postoperatif 3. haftada bant gevşetilmiş ve bu hastalarda SUI tekrarlamamıştır. Bizim çalışmamızda, postoperatif erken dönemde, idrar yapamayan bir hasta tekrar kateterize edilerek postoperatif 48 saat sonra sondası çekildi. Hasta idrarını 1kınarak yaptığını tarif etti. Bakılan rezidü idrarı $100 \mathrm{~mL}$ 'nin altında idi. Hiçbir hastada bantın tekrar ayarlanması gerekmedi.

TOT sonras1 de nova urge oranını Grise ve ark. [15] \%10,9; Isabelle Kaelin ve ark. [20] $\% 6,2$ olarak bulmuştur. Hayat kalitesi üzerindeki en güçlü negatif etki olan de nova urge, TVT'ye oranla 3 kat daha az rapor edilmektedir [21]. Bu da, TOT'un obstrüktif etkisinin düşük olduğunu göstermektedir. Çalışmamızda, postoperatif de nova urge mesane instabilitesi olan iki $(\% 6,6)$ hasta oldu.

Diğer bir komplikasyon olan mesane perforasyonu; TVT'de \%0,8-\%21 oranında görülürken [22], TOT'da nadir vakalarda rastlanmıştır. Mesane perforasyonu görülen hastaların çoğunun daha önceden geçirilmiş pelvik organ prolapsusu operasyonu hikayesi olduğu gözlemlenmiştir, ya da aynı operasyon esnasında pelvik organ prolapsus tamiri veya histerektomi uygulanmışır. Minaglia ve ark. [23], TOT esnasında mesane perforasyonu olan 3 vaka bildirmişlerdir. $\mathrm{Bu}$ vakaların 2 tanesinin daha önceden geçirilmiş pelvik organ prolapsusu tamiri öyküsü vardır. Krauth ve ark. [24]'nın yaptığ1 çalışmada; TOT tekniği ile mesane perforasyon riskinin çok düşük olduğu ve bu oranın $\% 0,5$ olduğu görülmektedir. Sonuç olarak, daha önce prolapsus operasyonu öyküsü olan ve prolapsus cerrahisi aynı prosedür esnasında yapılacak olan hastalar için sistoskopi önerilebilir. Yine de, bizim çalışmamızda; daha önce sistosel operasyonu, Kelly plikasyonu geçiren hastalarda, mesane perforasyonu olmadi. Yalnızca bir hastada periüretral diseksiyon esnasında mesane perforasyonu oldu. Peroperatif mesane onarımı yapılarak TOT yapıldı. Hastada bir hafta katater kald1. Daha sonraki takiplerde hastada denova urge geliştiği tespit edildi.

Delorme'nin yayınladığı ilk çalışmada \%98 kür oranı vardı [9]. Costa ve ark. [11] 183 olguluk serisinde ise \%80,5 kür, \%7,5 iyileşme oranı saptamıştır. TOT işleminde kür oranı \%51-95 arasında değişmektedir [25]. TVT ve TVT-O işlemlerini karşılaştıran randomize kontrollü çalışmalarda; Rinne ve ark. [26] kür oranını TVT'de \%95, TVTO'da \%93; Liapis ve ark. [27] ise \%89-90 olarak bulmuşlardır. Bizim çalışmamızdaki başarımız, \%87,7 oran ile, literatürle benzerlik göstermektedir.

Hastalarımızın doldurdukları hayat kalitesi değerlendirme anketlerinin hepsinde istatistiksel anlamlı iyileşme söz konusudur. Hastaların sosyal hayatını değerlendiren IIQ7 ve inkontinans ile ilgili sorunlarını değerlendiren UDI-6 skorları da anlamlı ölçüde 
düzelmiştir. İdrar kaçırmanın, günlük hayata olumsuz etkisi ve ruhsal durum üzerine etkisini araştıran IIQ-7 testi, urge ve stres inkontinans varlı̆̆ını araştıran UDI-6 testinin ilk 4 sorusuna verilen cevaplar, hastalarımızın kür oranını yansıtmaktadır. Yine UDI-6 testinin 5'inci ve 6'incı sorularına verilen yanıtlar, postoperatif obstrüksiyon ve retansiyon ile karşılaşmadığımızı göstermektedir.

Sonuç olarak; TOT işlemi üriner inkontinans tedavisinde yaşam kalitesini artıran etkin, güvenilir ve kolay uygulanabilir, düşük komplikasyon oranına sahip olan öğrenilmesi kolay bir ameliyat tekniğidir. Doğru endikasyon ile anatomiye hakim olarak yapıldığında başarı oranı \%100'lere yaklaşmaktadır. Fakat daha uzun takipli, farklı askı operasyonlarının karşılaştırıldığı yeni çalışmalar daha ayrıntılı bilgiler sağlayacaktır.

\section{Kaynaklar}

1. Abrams P, Blavias JG, Stanton SL, Andersen JT. The standardisation of terminology of lower urinary tract function. The International Continence Society Committee on Standardisation of Terminology. Scand J Urol Nephrol Suppl 1988; 114: 5-19.

2. Hunskaar S, Lose G, Sykes D, Voss S. The prevalence of urinary incontinence in women in four European countries. BJU Int 2004; 93: 324-30.

3. Biri A, Durukan E, Maral I, Korucuoğlu U, Biri H, Týraş B, Bumin MA. Incidence of stress urinary incontinence among women in Turkey. Int Urogynecol J 2006; 17: 604-10.

4. Dainer M, Hall CD, Choe J, Bhatia NN. The Burch procedure: a comprehensive review. Obstet Gynecol Surv 1999; 54: 49-60.

5. Petros PE, Ulmsten UI. An integral theory and its method for the diagnosis and management of female urinary incontinence. Scand J Urol Nephrol 1993; 153: 193.

6. Ulmsten U, Falconer C, Johnson P, Jomaa M, Lannér L, Nilsson CG, Olsson I. A multicenter study of tension-free vaginal tape (TVT) for surgical treatment of stress urinary incontinence. Int Urogynecol J 1998; 9: 210-3.

7. Ward KL, Hilton P; UK and Ireland TVT Trial Group. A prospective multicenter randomized trial of tension-free vaginal tape and colposuspension for primary urodynamic stress incontinence: Two-year follow-up. Am J Obstet Gynecol 2004; 190: 324-31.

8. Wang AC, Chen MC. Comparison of tension-free vaginal taping versus modified Burch colposuspension on urethral obstruction: a randomized controlled trial. Neurourol Urodyn 2003; 22: 185-90.

9. Delorme E.Transobturator urethral suspension: Mini-invasive procedure in the treatment of stress urinary incontinence in women. Prog Urol 2001; 11: 1306-13.

10. Delorme E, Droupy S, de Tayrac R, Delmas V. Transobturator tape (Uratape): a new minimally-invasive procedure to treat female urinary incontinence. Eur Urol 2004; 45: 203-7.

11. Costa P, Grise P, Droupy S, Monneins F, Assenmacher C, Ballanger P, Hermieu JF, Delmas V, Boccon-Gibod L, Ortuno C. Surgical treatment of female stress urinary incontinence with a trans-obturator-tape (T.O.T.) Uratape: short term results of a prospective multicentric study. Eur Urol 2004; 46: 102-6.

12. Delmas V. Anatomical risks of transobturator suburethral tape in the treatment of female stress urinary incontinence. Eur Urol 2005; 48: 793-8.

13. Ward KL, Hilton P, Browning J. A randomized trial of colposuspension and tension free vaginal tape for primary genuine stress incontinence. Neurourology urodynamics 2000; 19: 386-8.

14. Latthe PM, Singh P, foon R, Toozs-Hobson P. Two routes of transobturator tape procedures in stress urinary incontinence: A meta-analysis with direct and indirect comparison of randomized trials. BJU Int 2011; 106: 68-76. 
15. Grise P, Droupy S, Saussine C, Ballanger P, Monneins F, Hermieu JF, Serment G, Costa P. Transobturator tape sling for female stress incontinence with polypropylene tape and outside-in procedure: prospective study with 1 year of minimal follow-up and review of transobturator tape sling. J Urol 2006; 68: 75963.

16. Fitzgerald MP, kenton K, Shott S, Brubaker L. Responsiveness of quality of life measurements to change after reconstructive pelvic surgery.Am J Obstet Gynecol 2001; 185: 20-4.

17. Klutke C, Siegel S, Carlin B, Paszkiewicz E, Kirkemo A, Klutke J. Urinary retention after tension-free vaginal tape procedure: Incidence and treatment. Urology 2001; 58: 697-701.

18. Lo TS, Wang AC, Horng SG, Liang CC, Soong YK. Ultrasonographic and urodynamic evaluation after tension free vagina tape procedure (TVT). Acta Obstet Gynecol Scand 2001; 80: 65-70.

19. Deval B, Ferchaux J, Berry R, Gambino S, Ciofu C, Rafii A, Haab F. Objective and subjective cure rates after trans-obturator tape (OBTAPE) treatment of female urinary incontinence. European Urology 2006; 49: 373-7.

20. Kaelin-Gambirasio I, Jacob S, Boulvain M, Dubuisson JB, Dallenbach P. Complications associated with transobturator sling procedures: analysis of 233 consecutive cases with a 27 months follow-up. BMC Womens Health 2009; 9: 28.

21. Holmgren C, Nilsson S, Lanner L, Hellberg D. Long-Term Results With TensionFree Vaginal Tape on Mixed and Stress Urinary Incontinence. Obstet Gynecol 2005; 106: 38-43.

22. Levin I, Groutz A, Gold R, Pauzner D, Lessing JB, Gordon D. Surgical complications and medium-term outcome results of tension-free vaginal tape: a prospective study of 313 consecutive patients. Neurourol Urodyn 2004; 23: 7-9.

23. Minaglia S, Ozel B, Klutke C. Bladder injury during transobturator sling. Urology 2004; 64: 3761-2.

24. Krauth JS, Rasoamiaramanana H, Barletta H, Barrier PY, Grisard-Anaf M, Lienhart J, Mermet J, Vautherin R, Frobert JL. Sub-urethral tape treatment of female urinary incontinence--morbidity assessment of the trans-obturator route and a new tape (I-STOP): a multi-centre experiment involving 604 cases. Eur Urol 2005; 47: 102-6.

25. Houwert RM, Renes-Zijl C, Vos MC, Vervest HA. TVT-O versus Monarc after a 2-4-year follow-up: a prospective comparative study. Int Urogynecol J Pelvic Floor Dysfunct 2009; 20: 1327-33.

26. Rinne K, Laurikainen E, Kivelä A, Aukee P, Takala T, Valpas A, Nilsson CG. A randomized trial comparing TVT with TVT-O: 12-month results. Int Urogynecol J Pelvic Floor Dysfunct 2008; 19: 1049-54.

27. Liapis A, Bakas P, Giner M, Creatsas G. Tension-free vaginal tape versus tension-free vaginal tape obturator in women with stress urinary incontinence. Gynaecol Obstet Invest 2006; 62: 160-4. 